\title{
SISTEM PENDUKUNG KEPUTUSAN PENERIMAAN BEASISWA DENGAN MENGGUNAKAN METODE SIMPLE ADDITIVE WEIGHTING (SAW) STUDI KASUS POLITEKNIK HARAPAN BERSAMA TEGAL
}

\author{
Yerry Febrian Sabanise ${ }^{1}$, Arif Rakhman ${ }^{2}$ \\ Email : yerryfebrian@gmail.com, cakrakirana7@gmail.com \\ Teknik Komputer Politeknik harapan Bersama Tegal \\ Jl. Mataram no 9 Kota Tegal Jawa Tengah (0283) 352000
}

\begin{abstract}
Abstrak
Beasiswa merupakan pemberian bantuan berupa keuangan yang diberikan kepada perorangan yang bertujuan untuk digunakan demi keberlangsungan Pendidikan yang di tempuh. beasiswa Dalam menentukan mahasiswa yang layak menerima beasiswa, bagian kemahasiswaan memerlukan system untuk mempercepat proses pemberian beasiswa. Oleh karena itu dibutuhkan system pendukung keputusan yang memudahkan bagian kemahasiswaan untuk menentukan mahasiswa yang layak mendapatkan beasiswa. System pendukung keputusan ini menggunakan metode simple additive weighting (SAW) yang membutuhkan proses normalisasi matrik keputusan (x) ke suatu skala yang dapat di perbandingkan dengan semua rating alternatif yang ada. Kriteria yang digunakan adalah IPK,Penghasilan orang tua, semester, usia. Hasil penelitian ini berupa aplikasi system pendukung keputusan penerimaan beasiswa menggunakan metode simpel additive weighting (SAW) yang berguna untuk memudahkan dalam menentukan mahasiswa yang layak mendapatkan beasiswa dan mahasiswa yang tidak layak mendapatkan beasiswa.
\end{abstract}

Kata kunci : Beasiswa, SAW, system pendukung keputusan, mahasiswa

\section{Pendahuluan}

Beasiswa merupakan suatu program pengembangan yang didapatkan mahasiswa untuk terus dapat melanjutkan studi, baik berupa bantuan biaya, dengan berbagai kegiatan seminar maupun pelatihan. Selain untuk menunjang biaya Pendidikan, beasiswa juga merupakan sebuah penghargaan untk mahasiswa karena terdapat golongan beasiswa yang diperoleh atas prestasi yang diperoleh seseorang.

Penawaran beasiswa diperguruan tinggi sangatlah banyak dan beragam jenisnya, terdapat beasiswa untuk mahasiswa kurang mampu, dan juga beasiswa mahasiswa berprestasi. Keuntungannya beragam, mulai dari uang, pelatihan, tunjangan Surat Persetujuan Pembayaran (SPP) dan lainnya.

Adapun jenis beasiswa yang ada di Politeknik Harapan Bersama Kota Tegal adalah beasiswa peningkatan prestasi akademik (PPA), bantuan belajar mahasiswa (BBM) yang saat ini disebut Bantuan Biaya Pendidikan PPA (BBP), dan surat Perintah Sebelas Maret (supersemar)

Didalam dunia Pendidikan pemberian Beasiswa kepada Mahasiswa adalah kegiatan rutin. Dalam pelaksanaan sering terjadi beasiswa yang tidak tepat sasaran. Dalam pemberian beasiswa kepada mahasiswa bagian kemahasiswaan wajib menganalisis mahasiswa berdasarkan kriteriakriteria yang telah ditetapkan. Kemahasiswaan harus mampu mengambil keputusan yang tepat dalam menerima pengajuan beasiswa atau menolak pengajuan beasiswa.

Sistem pendukung keputusan merupakan system informasi interaktif yang menyediakan informasi, pemodelan, dan pemanipulasian data. System itu digunakan untuk membantu pengambilan keputusan dalam situassi yang semiterstruktur dan situasi yang tidak terstruktur, dimana tak seorang pun tahu secara pasti bagaimana keputusan seharusnya dibuat [1].

Metode SAW sering dikenal juga dengan istilah metode penjumlahan terbobot. Konsep dasar metode SAW adalah mencari penjumlahan terbobot dari ranting kinerja pada setiap alternative pada semua atribut[2]. Metode SAW proses normalisasi matrik keputusan (X) ke suatu skala yang dapat di perbandingkan dengan semua rating alternative yang ada [3]

Berdasarkan penjelasan diatas, akan digunakan metode SAW untuk mengetahui mahasiswa yang layak mendapatkan beasiswa. Dengan menggunakan metode SAW yang akan diterapkan dalam system 
pengambilan keputusan diharapkan dapat membantuk bagian kemahasiswaan untuk memilih mahasiswa yang layak mendapatkan beasiswa berdasarkan kriteria-kriteria dan bobot yang telah ditentukan.

\section{Metode Penelitian}

a. Metode pengumpulan data mempunyai peran yang sangat penting karena berguna untuk memperoleh data-data yang nantinya akan diolah dan dianalisis sehingga mendapatkan hasil yang berkualitas. Hasil dari penelitian diharapkan memberi jalan keluar dari permasalahan yang sedang diteliti, metode yang digunakan dalam pengumpulan data adalah sebagai berikut

1) Wawancara (interview) Wawancara merupakan tanya jawab lisan antara dua orang atau lebih untuk mencapai suatu tujuan tertentu. Wawancara dilakukan guna memperoleh data dari interview atau orang yang diwawancarai yang berhubungan dengan topik penelitian dan melakukan eksplorasi terhadap masalah yang ada, kriteria apa saja yang menentukan mahasiswa layak menerima beasiswa apa saja syaratsyaratnya, dan apa sudah pernah menggunakan alat bantu dalam menentukan mahasiswa yang layak menentukan beasiswa.

2) Pengamatan (Observasi)

Dilakukan dengan mengumpulkan data dan informasi yang nanti akan digunakan untuk acuan dalam pembuatan system pendukung keputusan penerimaan beasiswa menggunakan metode SAW. Data dan informasi yang didapat dengan mengamati langsung yang berhubungan dengan penelitian yang dilakukan. b. Pengolahan Data

Dalam proses pengolahan data, ada beberapa langkah-langkah ilmiah yang perlu dilakukan agar hasil yang didapatkan baik, sebagai berikut :

1) Penyuntingan (Editing)

Penyuntingan adalah pengecekan atau pengoreksian data yang telah terkumpul yang berasal dari hasil wawancara dan jurnal, tujuannya untk menghilangkan kesalahan-kesalahan atau yang masih meragukan didalam hasil pencatatan dilapangan atau hasil wawancara dan bersifat koreksi

2) Pengkodean

Pengkodean adalah pemberian kode-kode pada setiap data yang termasuk dalam kategori yang sama. Kode adalah isyarat yang dibuat dalam bentuk angka atau huruf yang memberikan petunjuk atau identitas pada suatu informasi atau data yang dianalisis.

3) Tabulasi

Tabulasi adalah pembuatan table-tabel yang berisi data yang telah diberi kode sesuai analisis yang dibutuhkan dalam melakukan tabulasi diperlukan ketelitian agar tidak terjadi kesalahan.

c. Tahapan Pada Sistem

Tahapan yang digunakan pada system ini adalah :

1) Kriteria-kriteria yang digunakan untuk menentukan mahasiswa yang layak diberikan beasiswa seperti IPK, penghasilan orang tua, usia, dan prestasi.

2) Menentukan rating kecocokan setiap alternative berdasarkan nilai kriteria 
3) Melakukan matriks keputusan yang berasal dari rating kecocokan

4) Melakukan normalisasi matriks keputusan berdasarkan jenis atribut.

5) Mendapatkan mahasiswa yang layak menerima beasiswa berdasarkan metode SAW

\section{Hasil dan Pembahasan}

a. Perhitungan SAW

Langkah-langkah perhitungan SAW dalam menentukan mahasiswa yang layak menerima beasiswa dan mahasiswa yang tidak layak menerima beasiswa sebagai berikut :

1) Menentukan kriteria yang akan dijadikan acuan dan juga bobotnya, yaitu IPK, Penghasilan orang tua, Prestasi dan Usia.

Tabel 1 Kriteria

\begin{tabular}{|l|l|l|}
\hline & Kriteria & $\begin{array}{l}\text { Nilai } \\
\text { Bobot }\end{array}$ \\
\hline C1 & IPK & 3 \\
\hline C2 & $\begin{array}{l}\text { Penghasilan } \\
\text { orang tua }\end{array}$ & 3 \\
\hline C3 & Prestasi & 1 \\
\hline C4 & Usia & 2 \\
\hline
\end{tabular}

2) Melakukan rating kecocokan berdasarkan bobot setiap subkriteria Berikut adalah subkriteria dan bobot nilai yang telah ditentukan dalam menentukan mahasiswa yang layak menerima beasiswa :

a) IPK

Tabel 2

\begin{tabular}{|l|l|l|}
\hline $\begin{array}{l}\text { Kriteri } \\
\text { a IPK }\end{array}$ & $\begin{array}{l}\text { Tingkat } \\
\text { Kepentinga }\end{array}$ & $\begin{array}{l}\text { Nilai } \\
\text { Bobo }\end{array}$ \\
\hline
\end{tabular}

\begin{tabular}{|l|l|l|}
\hline & n Kriteria & $\mathrm{t}$ \\
\hline IPK & Kurang & 1 \\
$0,00-$ & & \\
2,74 & & \\
\hline IPK & Cukup & 2 \\
$2,75-$ & & \\
3,49 & & \\
\hline IPK & Tinggi & 3 \\
$3,50-$ & & \\
4,00 & & \\
\hline
\end{tabular}

b) Penghasilan Orang tua Tabel 3

\begin{tabular}{|c|c|c|}
\hline $\begin{array}{l}\text { Kriteria } \\
\text { Penghasi } \\
\text { lan }\end{array}$ & $\begin{array}{l}\text { Tingkat } \\
\text { Kepentin } \\
\text { gan } \\
\text { Kriteria }\end{array}$ & $\begin{array}{l}\text { Nila } \\
\text { i } \\
\text { Bob } \\
\text { ot }\end{array}$ \\
\hline $\begin{array}{l}> \\
4.000 .00 \\
0\end{array}$ & Kurang & 1 \\
\hline $\begin{array}{l}2.100 .00 \\
0 \quad- \\
4.000 .00 \\
0\end{array}$ & Cukup & 2 \\
\hline $\begin{array}{l}< \\
2.000 .00 \\
0\end{array}$ & \begin{tabular}{|l|} 
Tinggi \\
\end{tabular} & 3 \\
\hline
\end{tabular}

c) Prestasi

Tabel 4

\begin{tabular}{|l|l|l|}
\hline Kriteria & $\begin{array}{l}\text { Tingkat } \\
\text { Kepentin } \\
\text { gan } \\
\text { Kriteria }\end{array}$ & $\begin{array}{l}\text { Nila } \\
\text { i } \\
\text { Bob } \\
\text { ot }\end{array}$ \\
\hline $1-3$ & Kurang & 1 \\
$\begin{array}{l}\text { Sertifikat } \\
\text { Non } \\
\text { Akadedmi }\end{array}$ & & \\
\hline
\end{tabular}




\begin{tabular}{|l|l|l|}
\hline k & & \\
\hline \multicolumn{1}{|l|}{$\begin{array}{l}\text { Sertif } \\
\text { ikat } \\
\text { Regi } \\
\text { onal }\end{array}$} & Cukup & 2 \\
\hline $\begin{array}{l}\text { 3 - 5 } \\
\text { Sertifikat } \\
\text { Nasional }\end{array}$ & Tinggi & 3 \\
\hline
\end{tabular}

d) Usia

Tabel 5

\begin{tabular}{|l|l|l|}
\hline $\begin{array}{l}\text { Kriteri } \\
\text { a Usia }\end{array}$ & $\begin{array}{l}\text { Tingkat } \\
\text { Kepentinga } \\
\text { n Kriteria }\end{array}$ & $\begin{array}{l}\text { Nilai } \\
\text { Bobo } \\
\mathrm{t}\end{array}$ \\
\hline$>23$ & Kurang & 1 \\
\hline $20-$ & Cukup & 2 \\
\hline $18-20$ & Tinggi & 3 \\
\hline
\end{tabular}

Hasil dari rating kecocokan berdasarkan bobot dari setiap subkriteria adalah sebagai berikut :

\begin{tabular}{|c|c|c|c|c|}
\hline $\begin{array}{l}\text { Altern } \\
\text { atif }\end{array}$ & $\begin{array}{l}\text { Krite } \\
\text { ria }\end{array}$ & & & \\
\hline & $\mathrm{C} 1$ & $\begin{array}{l}\mathrm{C} \\
2\end{array}$ & $\begin{array}{l}\mathrm{C} \\
3\end{array}$ & $\begin{array}{l}\mathrm{C} \\
4\end{array}$ \\
\hline A1 & 3 & 3 & 1 & 3 \\
\hline A2 & 3 & 1 & 3 & 2 \\
\hline A3 & 2 & 3 & 2 & 2 \\
\hline A4 & 3 & 2 & 2 & 3 \\
\hline A5 & 2 & 3 & 3 & 2 \\
\hline
\end{tabular}

\begin{tabular}{|l|l|l|l|l|}
\hline A6 & 1 & 3 & 3 & 2 \\
\hline A7 & 3 & 2 & 3 & 3 \\
\hline
\end{tabular}

3) Membuat matriks keputusan dan melakukan normalisasi matriks :

Alternatif 1

$$
x=\left[\begin{array}{llll}
3 & 3 & 1 & 3 \\
3 & 1 & 3 & 2 \\
2 & 3 & 2 & 2 \\
3 & 2 & 2 & 3 \\
2 & 3 & 3 & 2 \\
1 & 3 & 3 & 2 \\
3 & 2 & 3 & 3
\end{array}\right]
$$

$r 1,1$

$=\frac{3}{\max (332331312331221)}$

$=\frac{3}{3}=1$

$$
\begin{aligned}
& r 1,2 \\
& =\frac{3}{\max (332331312331221)} \\
& =\frac{3}{3}=1
\end{aligned}
$$

$$
\begin{aligned}
& r 1,3 \\
& =\frac{2}{\max (332331312331221)} \\
& =\frac{2}{3}=0,66667 \\
& r 1,4 \\
& =\frac{3}{\max (332331312331221)} \\
& =\frac{3}{3}=1
\end{aligned}
$$




$$
\begin{aligned}
& r 1,5 \\
& =\frac{2}{\max (332331312331221)} \\
& =\frac{2}{3}=0,66667 \\
& r 1,6 \\
& =\frac{1}{\max (332331312331221)} \\
& =\frac{1}{3}=0,33333 \\
& r 1,7 \\
& =\frac{\max (332331312331221)}{3} \\
& =\frac{3}{3}=1
\end{aligned}
$$

Sampai dengan semua alternative yang ada hasilnya masukan kedalam matriks dan hasilnya adalah :

$x$

$$
=\left[\begin{array}{cccc}
1 & 1 & 0.33333 & 1 \\
1 & 0.33333 & 1 & 0.66667 \\
0.66667 & 1 & 0.66667 & 0.66667 \\
1 & 0.66667 & 0.66667 & 1 \\
0.66667 & 1 & 1 & 0.66567 \\
0.33333 & 1 & 1 & 0.66667 \\
1 & 0.66667 & 1 & 1
\end{array}\right]
$$

4) Hasil akhir dari proses perhitungan SAW adalah untuk mencari nilai vector $(\mathrm{Vi})$

$$
\begin{aligned}
& \mathrm{A} 1=(3 \times 1)+(3 \times 1)+(1 \times 0,33333)+( \\
& 2 \times 1)=3+3+0,33333+2=8,33 \\
& \mathrm{~A} 2=(3 \times 1)+(3 \times \times 0,33333)+(1 \times 1)+ \\
& (2 \times 0,66667)=3+0,99999+1+1,33 \\
& 334=6,33
\end{aligned}
$$

$\mathrm{A} 3=(3 \times 0,66667)+(3 \times 1)+(1 \times 0,66$ $667)+(2 \times 0,66667++)=2,00001+3$ $+0,66667+1,33334=7,00$

$\mathrm{A} 4=(3 \mathrm{x} 1)+(3 \mathrm{x} 0,33333)+(1 \times 0,66$ $667)+(2 \times 1)=3+0,99999+0,66667$ $+2=7,67$

$\mathrm{A} 5=(3 \mathrm{x} 0,66667++(3 \times 1)+(1 \times 1)+($ $2 \times 0,66667)=2,00001+3+1+1,333$ $34=7,33$

$\mathrm{A} 6=(3 \times 0,33333)+(3 \times 1)+(1 \times 1)+($ $2 \times 0,66667)=0,99999+3+1+1,333$ $34=6,33$

$\mathrm{A} 7=(3 \mathrm{x} 1)+(3 \mathrm{x} 0,66667)+(1 \mathrm{x} 1)+($ $2 \times 1)=3+2,00001+1+2=8,00$

Dengan demikian berdasarkan perhitungan SAW mahasiswa yang paling layak menerima beasiswa adalah alternative A1 dan untuk selanjutnya Batasan berapa nilai aleternatif yang lolos menerima beasiswa dapat ditentukan dengan mengambil nilai tengah atau nilai alternative > 6 tidak layak mendapatkan beasiswa atau juga dapat diabil menggunakan perangkingan dari nilai alternative yang ada.

\section{Kesimpulan}

1. Dari penelitian yang telah dilakukan, metode SAW dapat diimplementasikan dalam menyelesaikan masalah untuk menentukan kelayakan beasiswa mahasiswa dengan kriteria yang telah ditentukan yaitu IPK, penghasilan orang tua, prestasi dan usia.

2. Sistem ini membantu pengambilan keputusan dalam hal penghematan waktu yang dibutuhkan untuk mengambil keputusan pemberian beasiswa kepada mahasiswa dengan menggunakan metode SAW. 


\section{Daftar Pustaka}

[1] Candra Surya, Erliza Yubarda (2014), Penilaian Kinerja Dosen dalam Proses Pengajaran menggunakan Metode Fuzzy Attribute Decision Making dan Simple

[2] Candra Surya, Sistem Pendukung Keputusan (SPK) Pemilihan Perguruan Tinggi Swasta Menggunakan Fuzzy Multi Attribute Decision Making (FMADM) dan Metode Simple Additive Weighting (SAW), JIT Jurnal Velume 8 No. 1 Maret 2004

[3] Kusumadewi, Sri., Purnomo Hari., (2010), Aplikasi Logika Fuzzy Untuk Pendukung Keputusan Edisi 2

[4] Azhar Arsyad, Media Pembelajaran, PT. Raja Grafindo Persada, 2007.

[5] Rusman, Belajar dan Pembelajaran Berbasis Komputer. Bandung: Alfa Beta, 2012. 